\title{
E-government as an Effective Way of Interaction Between Government Authorities and the Population
}

\author{
Aleksey Ruchkin ${ }^{1, *}$ Tatiana Kruzhkova ${ }^{1}$ Olga Rushitskaya ${ }^{1}$ Gulnara \\ Dyuzelbayeva $^{2}$ \\ ${ }^{1}$ Ural State Agrarian University, Yekaterinburg, Russia \\ ${ }^{2}$ Kostanay Engineering and Economics University named after M. Dulatov, Kostanay, Kazakhstan \\ *Corresponding author. Email: alexeyruchkin87@gmail.com
}

\begin{abstract}
The issue of interaction between citizens and businesses with authorities during the pandemic has become particularly relevant in the context of self-isolation. E-government has become the only window of opportunity to receive state aid, appeals, and benefits. In this regard, it is necessary to constantly monitor the degree of user satisfaction with the capabilities of e-government and eliminate the shortcomings of the system. The purpose of our research is to conduct a survey of the population about the level of satisfaction with the quality and timing of public services, to identify key problems in obtaining services in electronic form. The study was conducted by questioning the population of the Sverdlovsk region at the age of 18 years, that is, citizens who have the right to apply personally, including in electronic form, for public services. The results obtained are verified with the results of previous studies conducted by other scientists: low level of computer literacy of the population, uncertainty in the preservation of personal data, as well as stable personal habits and preferences when applying for public services.
\end{abstract}

Keywords: Citizens, E-government, Use, Interaction, Business.

\section{INTRODUCTION}

E-government as a new system of organizing the activities of state and local government authority is one of the main points of implementation of modern administrative reform in the Russian Federation, which provides a qualitatively new level of interaction in the implementation of functions based on the use of information and communication technologies. Effective implementation of this concept requires the unity of elements of the e-government system at the Federal level, as well as at the level of subjects and their constituent municipalities. The problem is that there is not only no unified regulatory framework, but also a single set of implementation tools for the formation of e-government at the Federal level and in individual regions of the Russian Federation. The consequence of this problem is the low efficiency of the system functioning at the level of subjects, which does not allow achieving the targets of state programs related to the informatization of society. For example, by the beginning of 2018, satisfaction with the quality of services reached $86 \%$, and waiting time in the queue - 19 minutes, while the strategic targets for 2018 are $90 \%$ and 15 minutes, respectively (Federal state statistics service).

The effectiveness of the e-government system also negatively affects the demand for services provided in electronic form on the part of the population and organizations that prefer to receive them through personal contact, which is confirmed by the results of empirical research.

The e-government system that is being formed in the world and the Russian Federation is considered by researchers in the following aspects :

- analysis of the relevance of creating egovernment (Kaluti M., \& Rajani K. C., 2021); 
- analysis of e-democracy as a form of political communication (Yan, H., \& Ting, Y., 2018);

- e-government as a mechanism for influencing transaction costs in the public sector (Kautto T., \& Henttonen P., 2020; Pedrosa G. V. et all, 2020);

- research on the prospects of e-government development (SEPA V., 2021, Geteloma V. et all, 2019);

- features of interaction between government and society through the e-government system (Kamaruddin K. A. et all, 2018; Jacob D. W. et all, 2019; Liu D., 2018; Rihandoyo, 2018; Sonnenberg C., 2020; Kapsa, I., \& Musiał-Karg, M., 2020; Pakhalov a.m. et all, 2020).

The purpose of our research is to conduct a survey of the population about the level of satisfaction with the quality and timing of public services, to identify key problems in obtaining services in electronic form. Based on the goal, the authors formulated the following tasks: 1. Find out the degree of satisfaction with the quality of public services in electronic form, identify the shortcomings of providing these services in this format; 2. Determine the reasons why the population prefers to apply in person for public services instead of electronic advertising; 3. Identify the main disadvantages of providing public services in electronic form in the opinion of the population; 4. Develop recommendations for improving the quality of public services.

\section{METHODOLOGY}

The theoretical basis of the research is the concept of e-government. As a methodological base of research are used in the work system method: electronic government of Sverdlovsk region and is considered as a holistic system consisting of related elements and subsystems, and part of the system of organization of activity of government authority and of local self-government authority. This approach allowed us to reveal the features of the functioning of both individual elements and the system as a whole in the implementation of the main functions of government authority.

The study used the following research methods: empirical methods of evaluation and comparison.

The empirical base of the research is:

- statistical data describing the effectiveness of the functioning of the current e-government system (Information and analytical system for monitoring the quality of public services "Your control" and Federal state statistics service);
- results of a survey of the population of the Sverdlovsk region aged 18 and over in the number of 1013 people, aimed at determining the preferred sources of receiving services, reasons for refusal and preference for services in electronic form, as well as determining the assessment of the quality of services provided.

Based on the research carried out by the authors, new principles for developing the regulatory framework for the formation of an e-government system are proposed, as well as ways to popularize services in electronic form. Separately, the issues of improving the efficiency of the system functioning through moving system elements to the external environment or combining them into enlarged subsystems were considered.

\section{RESULTS}

Tasks associated with computer literacy and the level of Informatization of society, are not included in the list addressed by the e-government system, but a fundamental environmental factors for successful operation of the system, their solution is highlighted in the parental policy (information society), which is reflected in individual objectives, directions and routines of completed and ongoing government programs in Sverdlovsk region.

The effect of e-government policy measures is only spelled out in the program for 2016-2020. Success criterion:

1. Reducing the administrative burden on citizens and organizations associated with reducing the time they receive public services and necessary information;

2. Improving the efficiency of budget expenditures on the introduction of information technologies in the activities of state authorities of Sverdlovsk region (in General, the efficiency should have been 595 million rubles);

3. Reducing the cost of government agencies in Sverdlovsk region to organize the exchange of information at the interdepartmental level (efficiency of 739 million rubles).

So, the planned values were achieved for all indicators, except for some nuances:

1. Number of state and municipal services provided in electronic form is $81.6 \%$. the failure to achieve this indicator is due to the approval of new lists of state and municipal services to be converted to electronic form. This conclusion given in the report looks strange, since the target value for 2016 was much lower. 
2. The share of citizens using the mechanism for receiving state and municipal services in electronic form is $69.5 \%$, the decrease was caused by incorrect data provided by the Ministry of health in the previous period.

It can be judged that the implementation of the program was successful, since a number of other indicators (listed earlier in the tables) reached the target values. Unfortunately, the assessment of socioeconomic efficiency is not given in this document. as a result, we can only assess the effectiveness of policy implementation, but not its effectiveness. It can only be noted that in fact, during the implementation of the program in 2016, $87.2 \%$ of funds were spent in relation to the annual planned indicator, which indicates budget savings in the process of implementing the policy while maintaining the set results.

As of March 2019 (Information and analytical system...), a high percentage of errors was observed when providing information within the framework of interdepartmental interaction $-15 \%$, which indicates insufficient efficiency of the system (in accordance with the requirements of the Ministry of communications of Russian Federation, the figure should not exceed 1\%).

Other (albeit indirect) indicators of the effectiveness of policy implementation can be considered the position of the Sverdlovsk region in various ratings of Informatization of society.

The analysis of empirical data reveals a number of problematic points in assessing the effectiveness of policy implementation.

The first problem is the lack of a unified approach to assessing the effectiveness of policy implementation. The current state program lacks both the methodology for determining target indicators and the monitoring data itself. Data on the achievement of targets are published in reports on the implementation of the state program, where the indicator "the share of citizens using the mechanism for obtaining state and municipal services in electronic form" shows a figure of $69.5 \%$ for 9 months of 2019 . However, research data conducted in accordance with the Order of the Federal state statistics service "On approval of the methodology for calculating the indicator" the Share of citizens using the mechanism for receiving state and municipal services in electronic form " shows a figure of $42.5 \%$ in 2019 (33.6\% in 2018 and $51.2 \%$ in 2017).

In may 2019, the authors conducted their own empirical research in the form of an Internet survey. The object of the study is the population of the Sverdlovsk region aged 18 and over (citizens who have the right to apply for any state and municipal services in person), the sample was 1013 people. A special feature of the study is its form: only Internet users could take part in the survey, which excluded the appearance of statistical errors in the form of evaluating the quality of providing services in electronic form by citizens who did not apply for these services. The second feature is that the research is focused on assessing the quality of services provided and identifying the preferences of the population group that generally has all possible ways to get them.

The following results were obtained:

1. In the past year was $84.8 \%$ of the population had applied for state or municipal services

2. $78.6 \%$ of respondents prefer to use the unified portal of public services, $21.4 \%$ - services of multifunctional centers, $17.9 \%$ - personal appeal to the authority or Department, services directly on the portals of government received $10.7 \%$ of respondents

3 . The main reason for refusing to use services in electronic form is inconvenience $(37.5 \%)$, lack of Internet access $(37.5 \%)$ at the time of receiving the service, insufficient computer proficiency $(25 \%)$

4. The main reason for the inconvenience of receiving services in electronic form through a single portal or websites of departments is the inability to get the service in a fully electronic format $(72 \%)$ and the difficulty of finding the necessary information $(40 \%)$

5. The part of respondents who preferred contacting the MFC explained their preference for territorial accessibility (47.8\%) and the possibility of personal communication with an employee $(34.8 \%)$

6. Similarly, $45 \%$ of respondents who applied for a service directly to an institution or Agency note the possibility of personal communication as an advantage, and $36.4 \%$ explain their choice of not being able to receive the service in electronic form

7. $50 \%$ of respondents rate the quality of services provided at "good ", $32.1 \%$ - at "normal", $14.3 \%$ - at "excellent". $3.6 \%$ of respondents were completely dissatisfied

8. Specifically for services in electronic form, $39.3 \%$ rated "good ", $17.9 \%$ rated "excellent" and the same number rated "normal", $3.6 \%$ were completely dissatisfied with the services.

Based on the data obtained, conclusions can be drawn:

1. High percentage of preference for receiving services in electronic form is caused by the specifics of the research method-questionnaires via the Internet form, which accordingly formed an audience that has 
sufficient skills to use computer equipment and the Internet, and therefore has information about receiving services in electronic form

2. The factor of personal communication with the employee plays an important role in the process of receiving the service. One of the reasons is that there is no need to independently study the process of obtaining services, preparing documents, etc., since specialists of multifunctional centers have sufficient competence to explain the specifics of obtaining services to the applicant.

3. Respondents noted almost the same number of positive ratings of services received and in electronic form.

Thus, there is a significant gap between the data provided by the Ministry and the data of statistical research published on the website of the Federal state statistics service. Such a discrepancy in the figures does not allow us to conduct an accurate analysis of the effectiveness of the current system of providing services to the population in electronic form and take prompt measures to eliminate errors in operation. There is an imperfection of the research methodology: according to the state program, this indicator is calculated by the ratio of applications submitted for services in electronic form to the total number of applications, while in order to obtain up-to-date information, it is necessary to use indicators that reflect the ratio of specific subjects.

The second problem follows from the first one and consists in the fact that only quantitative indicators are used to assess the effectiveness and monitor the implementation of the e-government policy, while qualitative indicators are not affected. However, quantitative indicators such as "population share" rather determine the availability of services in electronic form and the degree of informing the population, while it is necessary to assess the quality of service delivery through a system for evaluating services directly by the recipient. Thus, according to the Vash Kontrol portal, at the level of the Russian Federation as a whole, approximately $86 \%$ of the population assess the level of services as "excellent", $10 \%$ - "good", 2.2\% - "normal", 0.8\% - "bad" and $1.5 \%$ - "very bad" (Information and analytical system...).

The third problem is the slow transition to providing state and municipal services in electronic form. In 2019, only 95 public services provided by the Executive authorities of the Sverdlovsk region were fully converted to electronic format (i.e., with the possibility of receiving the result of the service in electronic form), out of a total of 219 services (this indicator exceeds the indicators given in the Report on the implementation of the state program). Among the municipalities of the Sverdlovsk region, 28 do not implement the action plan for finalizing state and municipal services provided in electronic form through the RSPU, namely, they do not post information about services, electronic forms of documents required to receive services, and information about the structure and activities of local governments.

The next problem is the low assessment of the population of the Sverdlovsk region of e-government as a provider of state and municipal services in electronic form. The relevance of this problem is expressed in the data of statistical observation for 2019 (in the context of the Sverdlovsk region) (Federal state statistics service):

1. Only $36.5 \%$ of the population who applied for state and municipal services used official websites and portals of state and municipal services, $24.8 \%$ - in multifunctional centers.

2. $45.1 \%$ of the population who received services in electronic form (through official websites and portals) encountered problems.

3. $68.2 \%$ of recipients of electronic services were satisfied with the quality, $31.1 \%(37.5 \%)$ - partially satisfied, and $1.1 \%(0.9 \%)$ - completely dissatisfied with the quality of services. The share of those who are completely satisfied with the quality has increased, while the share of those who are not satisfied has slightly increased.

4. The main reason for refusing to receive services in electronic form $76.1 \%$ (77.8\% in the previous period - preference for personal visits and personal contacts. $10.1 \%$ (10\%) did not have sufficient skills to use the Internet, $7.6 \%$ faced the need for a personal visit and the provision of paper forms.

5. Only $0.7 \%$ of the population has a registered personal digital signature, and $28.2 \%$ of the regions population is registered on the unified portal of public services.

The data reveals the main problems that cause a low level of citizens requests for services in electronic form, the solution of which becomes the objectives of the project:

1. Low level of computer literacy of the population, insufficient for using the portal of public services. This conclusion is verified with the results of previous studies, including self-assessment of the development of their computer skills (Omelchenko et al., 2019; Chernova, 2019).

2. Fear for the safety of personal data. 
3. Stable personal habits of the population.

\section{CONCLUSION}

As recommendations for improving the state policy on the formation and operation of the egovernment system of the Sverdlovsk region, the following set of measures is proposed:

- Improving methods for monitoring and controlling the effectiveness of the e-government system.

The final indicators that justify the effectiveness of the system are two main ones: the percentage of the population receiving state and municipal services in electronic form, as well as the level of satisfaction with the services received. The latter indicator is of a qualitative nature and reflects the actual effectiveness based on the definition of "e-government" as a concept focused on the population and organizations as recipients of services. However, despite the existing methods of monitoring this indicator, it is not a key one and is not considered within the framework of the current legal acts of the Sverdlovsk region. The use of this indicator would make it possible to develop measures that would directly improve the quality of services provided within the framework of the state program. Using the feedback system will allow you to make adjustments to the process of providing those types of services that the population has problems getting.

It is also necessary to use a different methodology for estimating the proportion of the population receiving services in electronic form. The current assessment system used by the Ministry of transport and communications provides results that differ from the results of research by the Federal statistics service. It is likely that an assessment system is used that most closely matches the planned results set at the regional and Federal levels. However, these indicators do not reflect the actual situation, which creates obstacles to the development of measures to improve the system due to incorrect assessment of its impact on the external environment. It is necessary to make changes to the legal acts, according to which this indicator will be calculated based not on the ratio of applications for services in electronic form, but as the ratio of citizens who applied for services in electronic form to the total number of applicants. This indicator will reflect the effectiveness of using information resources to inform the population about receiving services through multifunctional centers or a single portal of public services, and in this case, the process of assessing the degree of satisfaction will be more objective: it will not evaluate the number of successfully rendered services, but their convenience and quality in relation to each specific applicant.

Another direction is the separation of control over the performance of state and municipal services, which is caused by different subjects of policy implementation (government authority and local selfgovernment authority). At the moment, the assessment of the quality of state and municipal services, as well as indicators of the share of the population receiving services in electronic form, as well as the share of services in electronic form, are combined, which is an incorrect approach.

- Excluding elements that perform duplicate functions from the system and replacing them with a single tool. Electronic document management and data storage systems play a special role here. This task can be implemented only after the development of a single solution that will replace various information systems with a single whole: for example, to combine electronic document management systems within and between departments. The use of electronic signature tools and cloud storage technologies will increase the level of transaction security in the process of interaction between participants. The presence of different systems requires both increased operating costs for their maintenance, and the need to train users of these systems in a set of skills, and in the process of transactions between systems - the need for manual data processing. A single information system will allow you to save money in both directions.

One of the most important steps is already being implemented - the introduction of a new electronic document management system based on the satellite ECM-platform and free software components was made in 2017, and at the moment it is being integrated into this system of municipalities.

The next step may be to create a single database for all authorities of the Sverdlovsk region: it is possible to combine it into a common system that includes both data entry and analysis modules and storage modules. As in the case of changing the platform of the electronic document management system, there will be a focus on standardization and unification of requests submitted to the system and information at the output, as well as increase the efficiency of the system due to a decrease in the resources used.

\section{AUTHORS' CONTRIBUTIONS}

Aleksey Ruchkin - conducting a sociological study, analyzing the results. Tatiana Kruzhkova development of recommendations and suggestions. Olga Rushitskaya - methodological justification of the 
study. Gulnara Dyuzelbayeva - literature review and problem analysis.

\section{REFERENCES}

[1] K.A. Kamaruddin, U.S. Marni, N.L.M. Noor, Conceptual model for assessment tool to measure citizen-centricity in E-government websites, Journal of Theoretical and Applied Information Technology 96(24) (2018) 8171-8182.

[2] M. Kaluti, \& K.C. Rajani. E-governance for public administration, 2021. DOI:10.1007/978981-15-7961-5_98

[3] D.W. Jacob, M.F.M. Fudzee, M.A. Salamat, T. Herawan, A review of the generic end-user adoption of e-government services, International Review of Administrative Sciences 85(4) (2019) 799-818. DOI:10.1177/0020852319861895

[4] V. Řepa, Digital transformation of public administration, 2021. DOI:10.1007/978-3-03049640-1_6

[5] D. Liu. User satisfaction management in egovernment: One k-means algorithm-based analysis, in: Paper presented at the 5th International Conference on Industrial Economics System and Industrial Security Engineering, IEIS 2018 - Proceeding, 2018. DOI:10.1109/IEIS.2018.8598086

[6] Rihandoyo, E-government evaluation on electronic procurement service (LPSE) user perspective, in: Paper presented at the E3S Web of Conferences, 2018, 73. DOI:10.1051/e3sconf/20187313015

[7] C. Sonnenberg, E-government and social media: The impact on accessibility, Journal of Disability Policy Studies 31(3) $2020 \quad$ 181-191. DOI:10.1177/104420732090652

[8] V. Geteloma, C.K. Ayo, R.N. Goddy-Wurlu, A proposed unified digital id framework for access to electronic government services, in: Paper presented at the Journal of Physics: Conference Series, 2019, 1378(4). DOI:10.1088/17426596/1378/4/042039

[9] T. Kautto, P. Henttonen, Records management as invisible work: A study of finnish municipalities, Government Information Quarterly 2020 37(4). DOI:10.1016/j.giq.2020.101460

[10] G.V. Pedrosa,, R.A.D. Kosloski, V.G. de Menezes, G.Y. Iwama, W.C.M.P. da Silva, R.M.D.C. Figueiredo, A systematic review of indicators for evaluating the effectiveness of digital public services, Information (Switzerland) 2020 11(10) 1-14. DOI:10.3390/info11100472

[11] I. Kapsa, M. Musiał-Karg, E-government in poland in public data and opinions of poles: Empirical analysis, in: Paper presented at the ACM International Conference Proceeding Series, 2020, 419-429. DOI: $10.1145 / 3428502.3428559$

[12] A.M. Pakhalov, N.A. Rozhkova, C. Alexopoulos, Assessing the quality of e-government services for entrepreneurship: A comparative study in russia's regions, in: Paper presented at the ACM International Conference Proceeding Series, 2020, 315-325. DOI:10.1145/3428502.3428546

[13] H. Yan, Y. Ting, The effectiveness of online citizen evaluation of government performance: A study of the perceptions of local bureaucrats in China, Public Personnel Management 47(4) (2018) 419-444. DOI:10.1177/0091026018767475

[14] I.B. Omelchenko, O.V. Zabelina, F.I. Mirzabalayeva, Self-assessment of the working population of their skills in the conditions of digitalization of the economy, Labor Economics 6 (1) (2019) 63-76. (In Rus.)

[15] V. Y. Chernova, Russian consumer in the digital economy, Discussion 2 (93) (2019) 38-42. (In Rus.) 